\title{
Moving beyond CAD to an Object-Orientated Approach for Electrical Control and Instrumentation Systems
}

\author{
Peter E.D. Love ${ }^{\mathrm{a}}$, Jingyang Zhou ${ }^{\mathrm{a}}$, Jane Matthews ${ }^{\mathrm{b}}$ and David J. Edwards \\ ${ }^{a}$ Dept. of Civil Engineering, Curtin University, GPO Box U1987, Perth, WA 6845 \\ ${ }^{\mathrm{b}}$ Dept. of Construction Management, Curtin University, GPO Box U1987, Perth, WA 6845 \\ ${ }^{\mathrm{c}}$ School of the Built Environment, Birmingham City University, Birmingham City University, \\ Millennium Point, Curzon Street, Birmingham, B4, 7XG, United Kingdom
}

\begin{abstract}
The quality of computer-aided-design (CAD) generated 'As-built' documentation is evaluated for a High Voltage Switchgear System (HVSS), which forms part of a Supervisory Control and Data Acquisition up-grade within a geo-thermal power plant. A total of 267 CAD drawings for the HVSS were used to create a Systems Information Model (SIM) whereby the physical components and associated connections were constructed in an object orientated database. Throughout the modelling process a considerable amount of errors and information redundancy were identified and examples are presented. The aforementioned CAD drawings consumed 10,680 man-hours to produce in stark contrast to the 80 man-hours required to construct the SIM; thus illustrating the efficiency and effectiveness of SIM when compared to CAD for the design and documentation of electrical, control and instrumentation systems (ECIS). To realise this huge potential cost and productivity saving requires a shift in mindset and a move beyond the use of CAD, where there exists a 1:n relationship, to one that focuses on establishing a 1:1 relationship between objects in the SIM and components in the real world.
\end{abstract}

Keywords: 'As-built' documentation, computer-aided design, errors, systems information model

\section{Introduction}

Accurate and reliable electrical documentation is pivotal for managing and operating constructed facilities (Clayton et al., 1998). However, there is a propensity for 'As-built' documentation, which records the status of a facility at the completion of construction, to contain errors and considerable information redundancy (Gallaher et al., 2004; Love et al., 2014). Moreover, they often do not effectively express the information required to operate a facility. An array of factors contribute to this aforementioned scenario, including the working environment, and poorly designed processes and structures. When producing electrical instrumentation and control system (ECIS) drawings however, it has been suggested that use of Computer-Aided-Design (CAD) provides the medium for generating of poor quality 'As-built' documentation, which renders them obsolete during maintenance and operations (who suggested this - REF please?). 
Within the construction and engineering industry, Building Information Modelling (BIM) has progressively been employed to improve the management of information throughout a project's lifecycle. BIM is typically created using an array of integrated software applications for architectural, structural, heating ventilation and air conditioning, and hydraulic elements. Such elements have scale and geometry that can be visualized within the BIM. However, ECIS are void of scale and geometry making visualized in a three-dimensional (3D) view impossible; albeit, cable trays and components can be modelled. Consequently, ECIS practitioners rely upon CAD to detail the connection and relationship between components (Love et al., 2013).

\section{Documentation of ECIS in CAD}

Through CAD, electrical and system engineers may: experiment with various alternative design solutions; validate circuits more readily; and improve design accuracy. For example, the design of a bi-stable circuit can be readily checked in CAD (i.e. values of load resistance attributed to the various components). Similarly, faulty permanent magnet design previously posed significant problems for electrical engineers as it resulted in partial demagnetization. However, CAD's ability to verify the design's reasonability has been resolved. Other advantages offered by CAD for ECIS practitioners include an ability to:

- $\quad$ provide an understandable representation of the numerical results of what? (e.g. through graphs and other graphic devices);

- $\quad$ reduce the tediousness of solving common and complex equations;

- adapt simple numerical methods to solve complex problems that would be otherwise too time-consuming to undertake via manual calculations; and

- test the design efficacy (such as the maximum value of load resistance the design can support).

Typical types of drawings created within CAD for ECIS are: 1) block; 2) schematic; 3) termination; and 4) layout. In addition to these drawings, complementary cable schedules and 'Cause and Effect' (C\&E) diagrams augment information provided within documentation produced; though this is dependent upon the nature of the system that is being designed and documented.

Despite CAD's many palpable benefits, ECIS engineers are dogged by errors and omissions, especially as objects are often replicated on several different drawing types. In addition, concepts and requirements from several sources are translated onto documents and drawings in varying 
patterns. Often, the same information is replicated within several documents to form relationships between them. For example, different information about the same component will regularly be placed in various documents or drawings and so equipment and cable tags are often repeated. As a documentation package evolves it becomes increasingly difficult to ascertain which particular documents contain the same information or show related information. Monitoring and controlling documentation information accuracy and currency therefore forms a critical component of the engineering management process. Yet, the extant literature consistently demonstrates that effective audits are rarely undertaken due to time and financial constraints imposed on engineering firms (e.g., Lopez and Love, 2012). When meticulous audits are undertaken, errors and omissions are invariably found and consequently, several iterations of the documentation may be required Do you mean 'revisions of the documents'? Unfortunately, engineers who are subject to tight programmes of working and associated time constraints may distribute incomplete or inaccurate documentation to contractors.

Incorrect labelling, missing labels and omissions represent typical errors found in ECIS drawings (Love et al., 2013). Moreover, connections between various electrical? devices (represented as shapes and lines) can be distributed among several drawings. Unclear please rewrite plus I'm not clear as to what the significance of this sentence is Errors and omissions identified by engineers on-site invariably result in a 'Request for Information' (RFI) being raised which seeks to identify and resolve issues on-site to avoid potential contract disputes and claims at a later date (Tadt et al., 2012). Raising an RFI can be costly and may adversely impact upon the contractor's productivity. This is because, when RFIs are addressed, drawings must be up-dated to accommodate consequential changes and thus better reflect what is actually being constructed; when this process is not robustly executed, the quality of 'As-built' documentation produced is questionable.

\section{'As-built' Documentation within Electrical Engineering Projects}

'As-built' documentation represents a revised set of drawings submitted by a contractor upon completion of the works they were contracted to undertake. They reflect changes made in the specifications and working drawings during the construction process, and detail the exact dimensions, geometry, and location of all elements of the work completed under a contract. However, there is a proclivity for errors or omissions to be contained within the 'As-built' documentation as they are prepared using two-dimensional (2D) CAD (Love et al., 2013; Zhou et al., 2015). Increasing competition, schedule and financial pressures invariably manifest in the production of incomplete tender documentation that fails to reflect the scope of works required 
(Love et al., 2015). Consequently, tender prices may increase as contractors account for potential risks. During construction, drawings may need to be amended as RFIs and change orders arise. Such amendments are 'simply' highlighted on selected drawings rather than comprehensively revising all information produced (and effectively communicating such to all parties involved).

Research undertaken by Love et al. (2013), for example, found a component or device may occur on as many as 20 drawings in electrical contracts. When a change is required to a $2 \mathrm{D}$ drawing, the drawing and each corresponding view has to be manually updated thus a 1:n relationship exists. In this case, every single drawing where a component or device exists is required to be up-dated, which increases costs to an engineering firm, and thus adversely impacts their fee if a fixed fee had been agreed. Contrastingly, if a cost reimbursement contract is awarded to an engineering firm, then the financial considerations associated with amending documentation are accommodated; they are in this instance being 'paid' to repeatedly issue paper, irrespective of its quality (i.e., completeness and accuracy).

\section{Case Study}

Considering the paucity of research undertaken in this area, an exploratory case study approach was undertaken. This empirical inquiry sought to specifically investigate the potential inadequacies of 'As-built' documentation produced using CAD when compared to the SIM approach. The case study selected for the research was based upon 'As-built' documentation supplied by a instrumentation and electrical systems organization who had been awarded a contract to upgrade the Supervisory Control and Data Acquisition (SCADA) system of a power plant. . Essentially, a SCADA is a system operating with coded signals over communication channels so as to provide control of remote equipment in real-time. The control system may be combined with a data acquisition system by adding the use of coded signals over communication channels to acquire information about the status of the remote equipment for display or for recording functions. SCADA systems ensure management are provided with timely and accurate data that can be used to optimize the operation of plant. The researchers worked collaboratively with this organization to produce an equivalent SIM from the 'As-built' drawings that had been provided by them in a CAD format.

\section{Case Background}

The Philippines is situated in the Western Pacific Ocean and consists of 7,107 islands with circa 100 million inhabitants. It is located at the western fringes of the Pacific Ring of Fire and is subjected to frequent volcanic activity. This geographical position enables superb opportunities 
for 'green and renewable' geothermal harvesting which currently contributes to $18 \%$ of the country's electrical power. In the early 1970's, the Philippines and the New Zealand governments initiated the 'Colombo Plan' to investigate the potential geothermal power reserve of the island of Leyte. After a series of shallow and deep drillings, a number of wells were completed and used to supply steam for the turbines for the Tongonan-1 Geothermal Power Plant, which was constructed and commissioned in 1983.

The Energy Development Corporation (EDC) is the largest producer of geothermal energy in the Philippines, second largest in the world and has invested in geothermal, hydro and wind energy projects (REF). Green Core Geothermal, Inc. (GCGI) is a subsidiary of EDC and operates two geothermal power plants, Tongonan-1 and Palinpinon, in Leyte and Negros Oriental respectively; collectively, these plants have the capacity to generate 305 megawatts. The Tongonan- 1 power plant, which is the focus of the research presented in this paper, consists of three 37.5 megawatts units that cumulatively generate a total of 112.5 megawatts. Why was this plant chosen over the other one? Any reasons?

\section{Dataset: 'As-built' Documents}

The 'As-built' electrical documentation, comprising of 267 CAD drawings of a SCADA system, identified in Table 1, were provided to a instrumentation and electrical systems organization by a major international construction company. The SCADA system's initial design was undertaken by a Swiss electrical engineering company and it was estimated that the total number of drawings produced was approximately 1800.

\begin{tabular}{|c|l|c|}
\hline Equipment & \multicolumn{1}{|c|}{ Drawing Type } & Number \\
\hline \multirow{4}{*}{$\begin{array}{c}\text { Common for } \\
\text { all Feeders }\end{array}$} & Cover sheet & 7 \\
\cline { 2 - 3 } & Index drawing & 4 \\
\cline { 2 - 3 } & Block diagram & 3 \\
\cline { 2 - 3 } & Schematic diagram & 9 \\
\cline { 2 - 3 } & Termination diagram & 15 \\
\cline { 2 - 3 } & Installation and designation & 17 \\
\hline
\end{tabular}




\begin{tabular}{|c|c|c|}
\hline \multirow{7}{*}{ Feeder 1} & Cover sheet & 1 \\
\hline & Index drawing & 6 \\
\hline & Schematic diagram & 13 \\
\hline & Termination diagram & 18 \\
\hline & Equipment technical data & 32 \\
\hline & Cable schedule & 2 \\
\hline & Layout diagram & 2 \\
\hline \multirow{7}{*}{ Feeder 2} & Cover sheet & 1 \\
\hline & Index drawing & 6 \\
\hline & Schematic diagram & 13 \\
\hline & Termination diagram & 18 \\
\hline & Equipment technical data & 31 \\
\hline & Cable schedule & 2 \\
\hline & Layout diagram & 2 \\
\hline \multirow{5}{*}{ Feeder 3} & Cover sheet & 1 \\
\hline & Index drawing & 5 \\
\hline & Schematic diagram & 9 \\
\hline & Termination diagram & 17 \\
\hline & Equipment technical data & 29 \\
\hline \multicolumn{2}{|r|}{ Total } & 267 \\
\hline
\end{tabular}

162

163 Would it not be better to move Figures 1 and 2 to after they are discussed not before? 


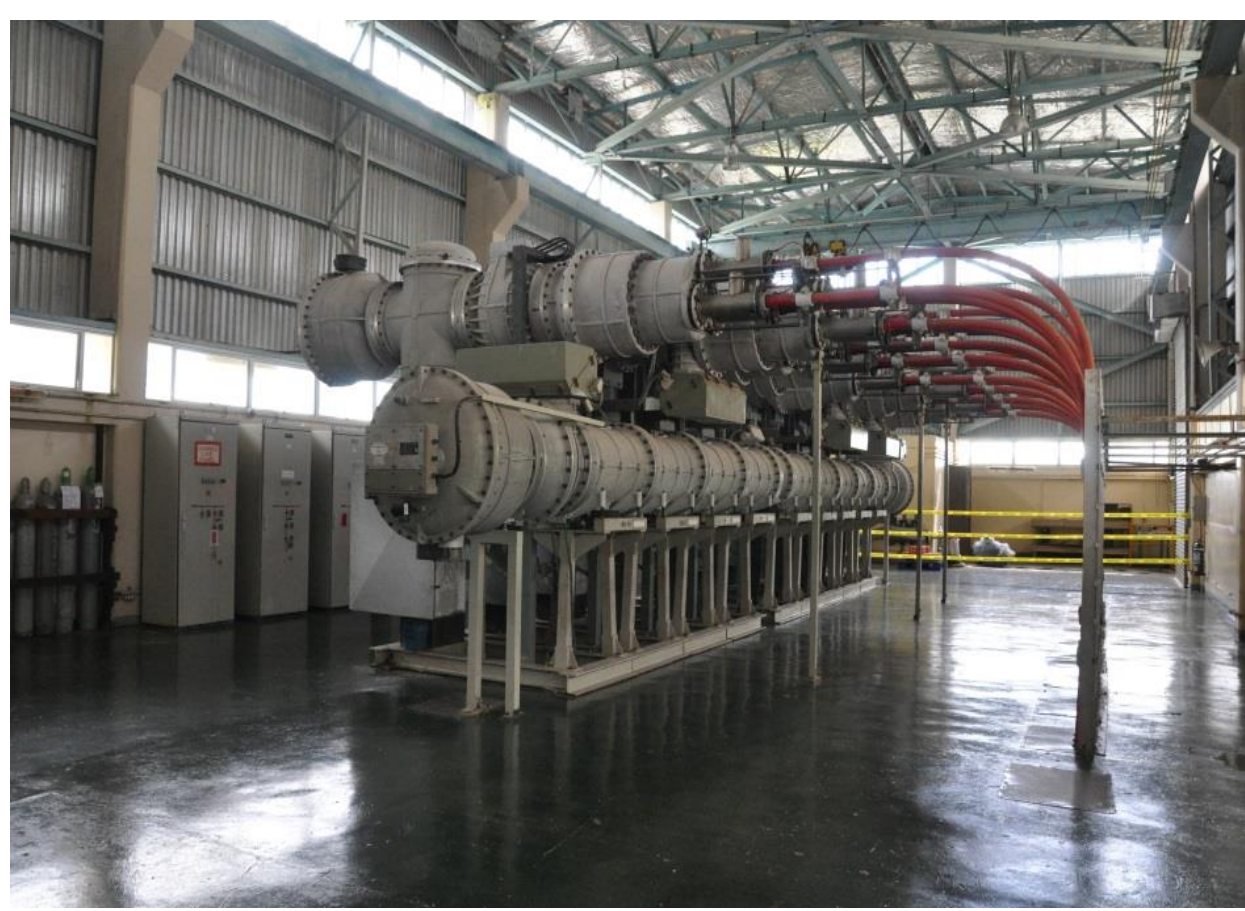

Figure 1. High voltage switchgears

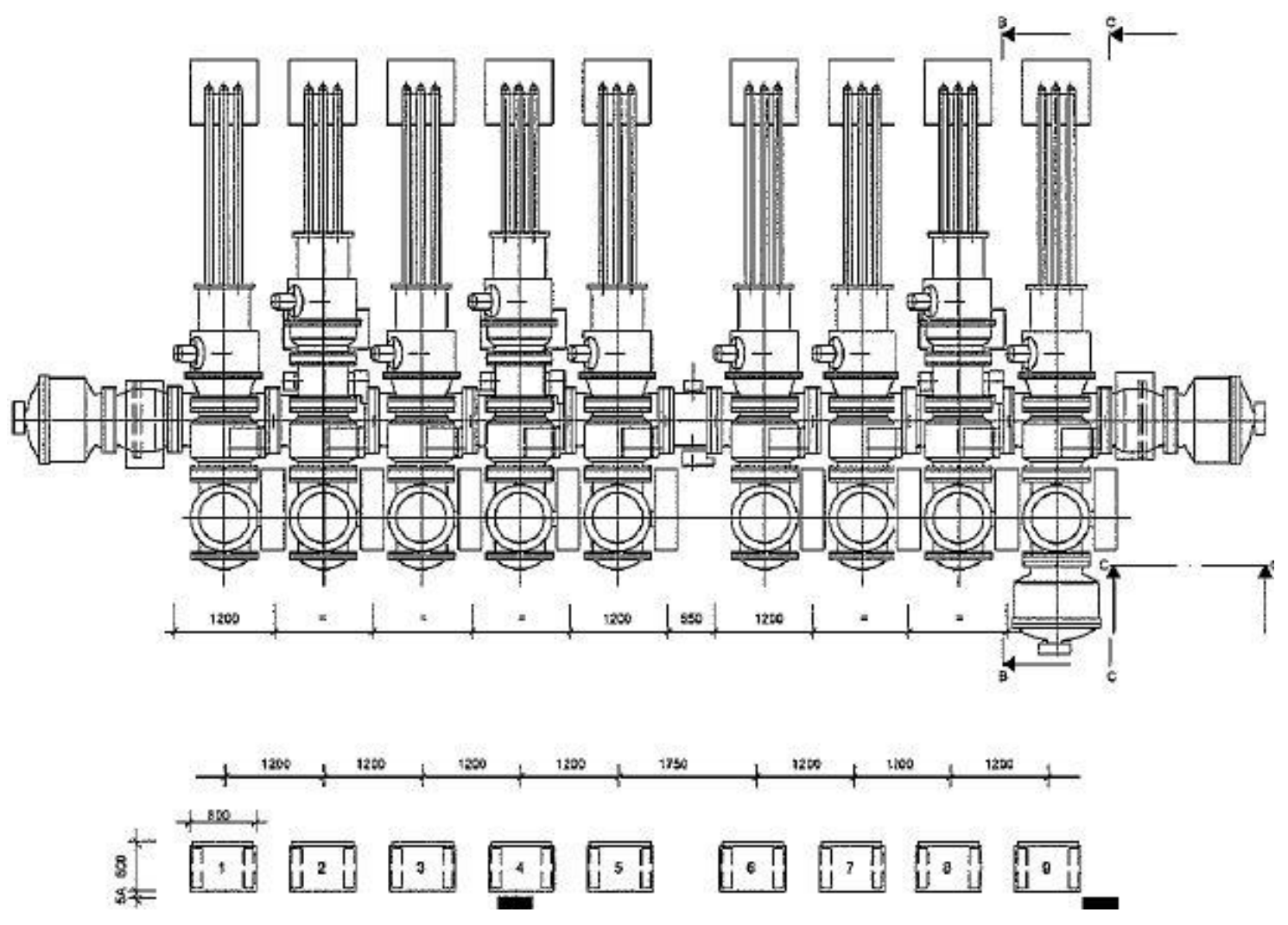

Figure 2. Layout of switchgears and control panels 
172 The supplied CAD drawings were used to document the design of the first three of nine high voltage (HV) switchgears for the plant's $138 \mathrm{kV}$ power Feeders (Figure 1). The layout of the switchgears and the corresponding control panels are presented in Figure 2. These HV switchgears are installed between generators and transformers and are critical for ensuring the power plant is operational. They act to protect equipment by clearing the short-circuit faults that could cause severe damage to them. Table 1 reveals that there are some common drawings that apply to all three Feeders. These drawings are used to demonstrate the general arrangement of the equipment, specify the designation for each individual device and illustrate the terminal connections for those commonly used sockets/plugs. Each Feeder has a corresponding set of specified drawings. The drawings indicate the equipment used for the switchgear and the panel side for each Feeder; interpanel cable connections and wirings between component terminals are also illustrated.

\section{Systems Information Modelling}

In evaluating the quality (i.e., information redundancy and errors) of the documentation provided, the electrical components and cables were digitally modelled into a SIM. A SIM is a generic term used to describe the process of modelling complex EICS using appropriate software (e.g., Dynamic Asset Documentation (DAD)) and is akin to the development of a Building Information Model (BIM). When a SIM is used to design and document a connected system, all physical components and associated connections to be constructed can be modelled in an object orientated database. This results in a 1:1 relationship between objects in the SIM and components in the real world. Consequently, errors and information redundancy typically contained within documentation developed in a traditional CAD system can be eliminated (Love et al., 2013; Love et al., 2014).

Two methods can be used to construct a SIM using software such as DAD: 1) manually; and 2) automatically. The manual method is appropriate for new projects or where a complete cable schedule is not available. In such circumstances, engineers are required to manually create a digital model of each real-world component and cable within the SIM to form a connected system. If complete cable schedules are available, then the modelling process is considered to be straightforward using software such as $\mathrm{DAD}$, as it is equipped with a function that can generate a SIM automatically based on the information derived from the cable schedules.

For this research, the available cable schedules only provided scant information about the interpanel cables. Hence, the information was insufficient to construct a SIM model automatically, particularly as internal cables within the inside panels were not made available to the 
instrumentation and electrical contractor. With this in mind, a SIM was manually created by the researchers in conjunction with the contractor's engineers. Can you briefly describe how this was done? When the modelling process was completed a total of 525 components and 2451 cables formed the basis of the SIM. The components were classified according to their 'Location' and 'Type'; that is, their physical location in the plant and their functionality (Figure 3). Cables were classified into various 'Types' according to the number of cores and their power rating. As a result, this enabled the design to be examined by directly reviewing the relationships of components through dynamically interconnected models rather than through the complicated connections presented on CAD drawings, which are invariably difficult to decipher.

\begin{tabular}{|c|c|}
\hline Location & Type \\
\hline \multicolumn{2}{|c|}{$\triangle \square$ Feeder 1} \\
\hline \multirow{2}{*}{\multicolumn{2}{|c|}{$\begin{array}{l}\square \text { HV Switchgear } 01 \\
\text { ПF01-CP01 }\end{array}$}} \\
\hline & \\
\hline \multicolumn{2}{|c|}{$4 \square$ Feeder 2} \\
\hline \multirow{2}{*}{\multicolumn{2}{|c|}{$\begin{array}{l}\square \text { HV Switchgear } 02 \\
\text { П } 02-C P 01\end{array}$}} \\
\hline & \\
\hline \multicolumn{2}{|c|}{$\triangle \square$ Feeder 3} \\
\hline$D \theta$ & HV Switchgear 0 \\
\hline ○ & L F03-CP01 \\
\hline$\square W_{0}$ & Vater Control Room \\
\hline$D$ Sta & tation Transformer \\
\hline$D \operatorname{Re}$ & elay Room \\
\hline
\end{tabular}

Figure 3. Location and type classification

Previous empirically research undertaken by Love et al. (2013) revealed that an average of five components and cables (10 objects in total) requires one CAD drawing. Bearing this in mind, the 2976 objects ( 525 components plus 2451 cables) modelled in this case would require approximately 297 CAD drawings, which is akin to the number supplied. Love et al. (2013) also revealed that 40 man-hours, on average, were required to produce each CAD drawing of an ECIS design. Thus, it is estimated that a total of 10,680 man-hours would be required to produce the 267 drawings. In addition, producing a complete set of 1800 project drawings would require a total of 72,000 manhours. Having established an estimate of workload, the quality of the 'As-built' documentation, as a result of creating the SIM, could now be assessed in accordance with the information redundancy and errors contained within the 267 electrical CAD drawings that were provided. 
231 The frequency of components among various locations on the drawings is provided in Table 2.

232

233

234

235

236

237

238

239

240

Table 2. Distribution of components

\begin{tabular}{|l|c|}
\hline \multicolumn{1}{|c|}{ Location } & Number of components \\
\hline Feeder 1 & 174 \\
\hline Feeder 2 & 183 \\
\hline Feeder 3 & 156 \\
\hline Relay Room & 8 \\
\hline Station Transformer & 1 \\
\hline Water Control Room & 3 \\
\hline Total & 525 \\
\hline
\end{tabular}

Table 3. Components comparison between Feeders

\begin{tabular}{|l|c|c|c|}
\hline Different & Feeder 1 & Feeder 2 & Feeder 3 \\
\hline Feeder 1 & NA & 150 & 153 \\
\hline Feeder 2 & 57 & NA & 147 \\
\hline Feeder 3 & 24 & 45 & NA \\
\hline
\end{tabular}

When Feeder 1 is compared with Feeder 2, a total of 150 identical and 57 different components (24 from Feeder 1 and 33 from Feeder 2) are detected. Explicitly, most of the components (over $86 \%$ ) of Feeder 1 will be replicated and used in Feeders 2 and 3. Consequently, the time to produce 
the SIM is significantly reduced, especially as software such as DAD provides the users with functionality that enables them to reproduce models using a 'Clone' command (Figure 4). Figure 4 illustrates the two options provided to users; namely: 1) 'Clone'; and 2) 'Clone with Connections'. If the 'Clone' command is used, only the chosen components are replicated. If the 'Clone with Connections' command is used, both the components and cables are replicated. Noteworthy, all the objects that are cloned will have identical features and attributes as their source objects.

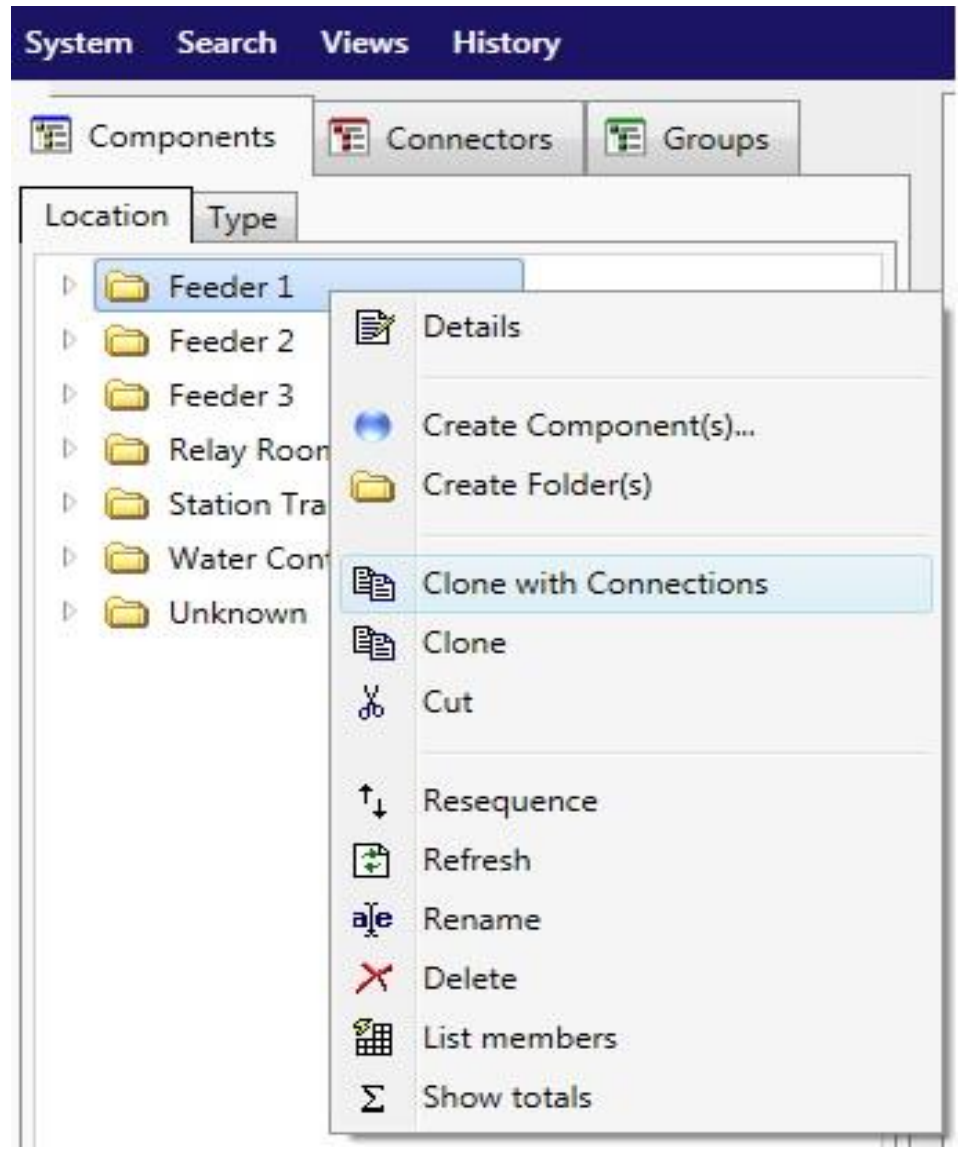

Figure 4. 'Clone' Function

261 As the functionality of the components and cables are similar for each of the Feeders, the function 262 'Clone with Connections' is used. The creation of the SIM for Feeder 1 is first developed and on completion is cloned to produce the models for Feeders 2 and 3. Then, the cables from the Feeders and control rooms are joined to form a single SIM. From Tables 2 and 3 it can be seen that through 'cloning', 82\% of the components in Feeder 2 and 98\% of the components in Feeder 3 can be modelled instantly by replicating the corresponding components in Feeder 1. On completion of the model for Feeder 1, those for Feeder 2 and Feeder 3 are also deemed to be almost finished. Using this approach the 'cloning' function reduced the time and effort of the modelling process 
by as much as two-thirds. When CAD is employed, each Feeder requires a specific set of drawings with the same information being reproduced (Table 1). These drawings are produced manually and as a result of complex relationships between components and cables, and the need to ensure the traceability of information, this becomes an arduous and tedious task for engineers and draftsmen. This manually-laden process significantly increases the propensity for human errors and omissions to be committed.

\section{Information Redundancy}

The distribution of components contained within the drawings was also examined. Figure 5 illustrates the distribution of the 525 components on each of the 267 CAD drawings; five drawings each contained over 100 components whilst one contained more than 200 components. This finding was expected as these drawings were common for all Feeders containing the definitions and designations of the components. However, 45 drawings had no components recorded on them. Essentially, they consisted of cover sheets, index and definition of drawings, which are timeconsuming and expensive to develop, but do not provide adequate information to ensure system integrity.

Most information contained on drawings was considered irrelevant to the electrical system design by the engineers (not sure that you say anywhere how many engineers were spoken to? Maybe add this detail earlier in the narrative?) who actively participated with researchers; the information mainly pertained to recording the title block, document number, revisions, drawing sheet specifications and notions. Documenting such information is an onerous and costly process and is typically the responsibility of a draftsman. If a mistake or omission arises a new revision of the entire drawing will have to be reproduced and reissued. This is an inefficient and ineffective method, which adversely impacts the productivity of the design and documentation process (Love et al., 2014). Pete - this text here seems like a repeat of earlier text....

The number of drawings that are linked to each component was calculated and thus provided a measure of system design complexity. Research revealed that, on average, each component could approximately be presented on five various drawings (Love et al., 2013; 2014). This figure Figure 5 ? typically provides the basis for determining the estimated workload prior to performing the task of producing the detailed design. 


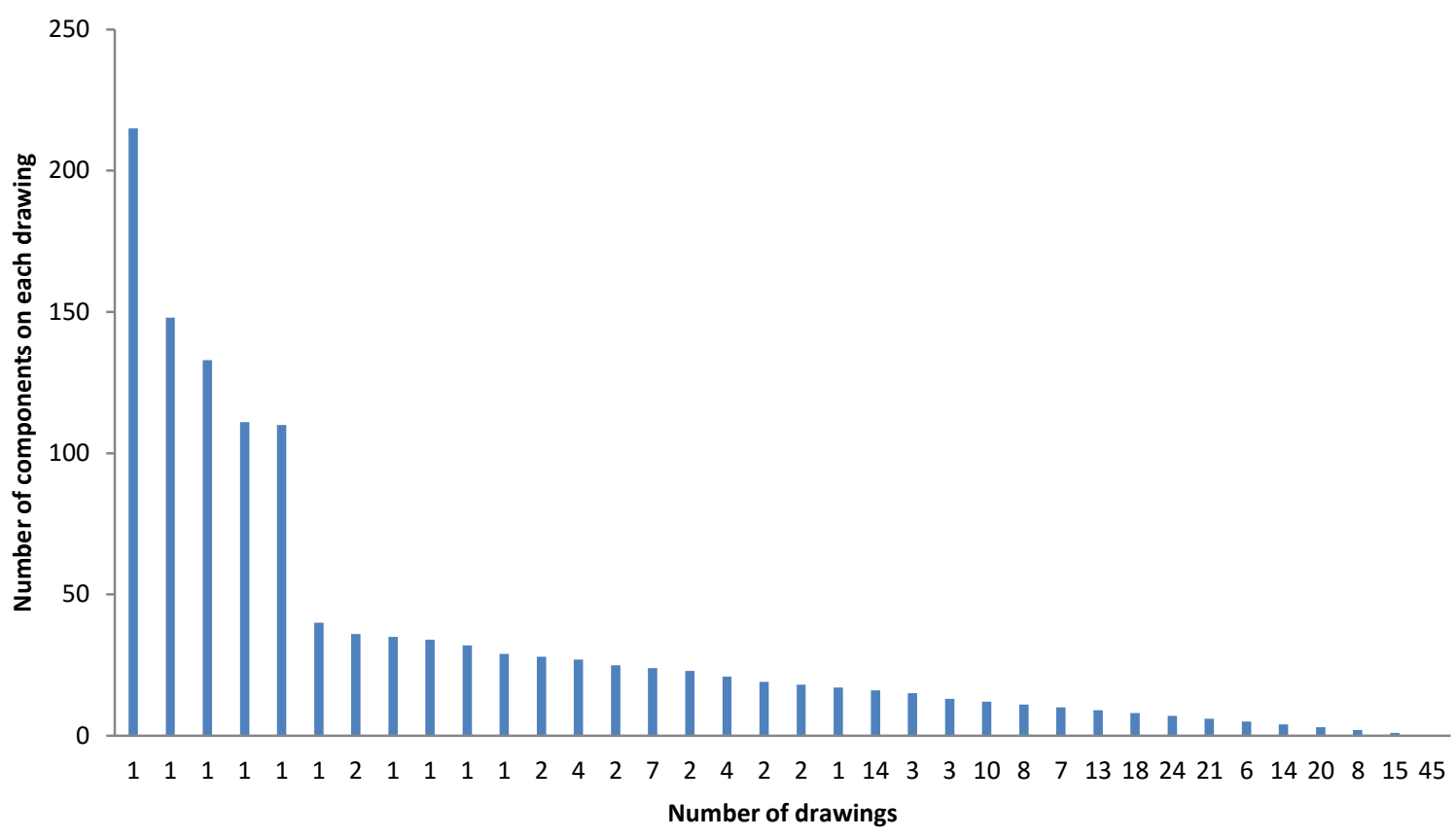

302

304

305

306

307

308

309

310

311

312

313

314

315

316

317

318

319

320

321

322

Figure 5. Distribution of components on each drawing

Figure 6 illustrates that a significant number of components appeared on more than ten drawings and three occurring on more than 20 drawings Not quite sure what you mean here. Most of these components are 48 pin sockets and terminal blocks, which are connected to multiple pieces of equipment. Considering the sheer number of components that were documented on a widespread of drawings, the propensity for draftsman to create an error (by placing sockets in the wrong location) significantly increases. A majority of the components (total 422 components, over 80\% of the 525 components) were found to reside on two to seven drawings. In this instance, each component will appear on average on 4.4 drawings, which is akin to empirical research promulgated by Love et al. $(2013$; 2014). Thus, the design complexity is considered to be 'standard' in this case.

As the original design was documented using CAD, each of the components would have been manually reproduced approximately five times on different drawings. Engineers and draftsmen must determine the types of drawings required (e.g., block, layout and schematic) and the information contained within each to facilitate effective communication amongst all projects parties regards what is to be physically constructed and installed. Noteworthy, no universal standard exists for documenting and producing different electrical drawings, which can hinder an engineer's ability to understand them. When errors or omissions are identified on a drawing, the 
contractor's engineer must examine all other related drawings and documents to determine which one is correct or simply raise a RFI; either way these are non-value adding activities.

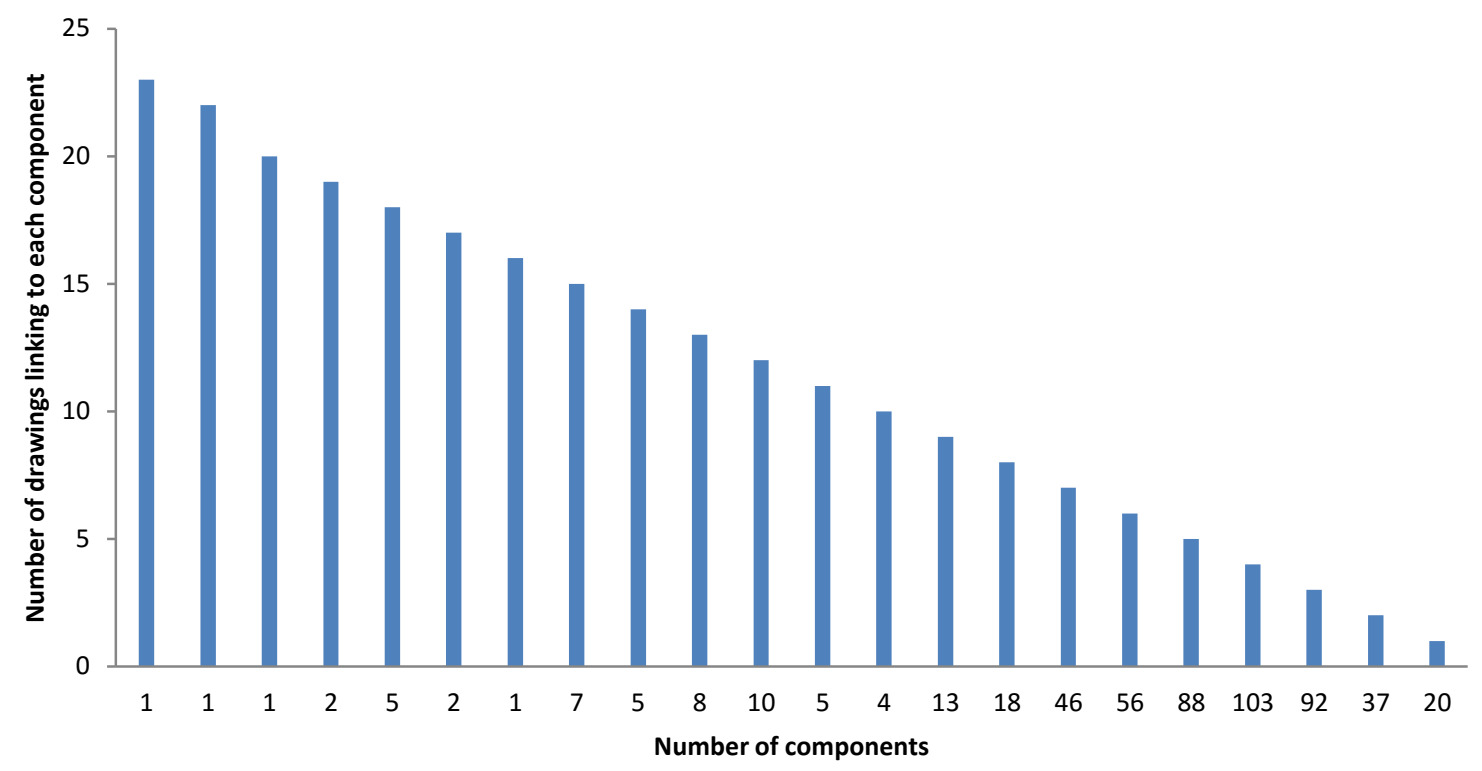

325

326

327

328

329

330

331

332

333

334

335

336

337

Figure 6. Number of drawings linked to each component

\section{Error Identification}

During the creation of the SIM, a plethora of errors (frequency $(f)=89)$ and omissions $(f=49)$ were discovered on the CAD drawings (Table 4 not sure we need this table when it can be explained in the text). For example, in Figure 7, it is shown that terminals X1 and X2 of a 'pressure switch F250' are connected to terminals A11 and A10 of a socket X250, respectively. However, the terminal X0 of F250 is connected to terminal B12 of X250, which is shown to be unusual compared with the connections ( $\mathrm{Y}$ terminals) next to it; all the three $\mathrm{Y}$ terminals ( $\mathrm{Y} 0, \mathrm{Y} 1$ and $\mathrm{Y} 2$ ) are connected to terminals B3, B2 and B1 of X250 respectively. Notably, there is no mismatch between A and B terminals. An examination of the drawings revealed that the 'pressure switch F250' appeared on eight drawings and the socket X250 on 14 of them. 


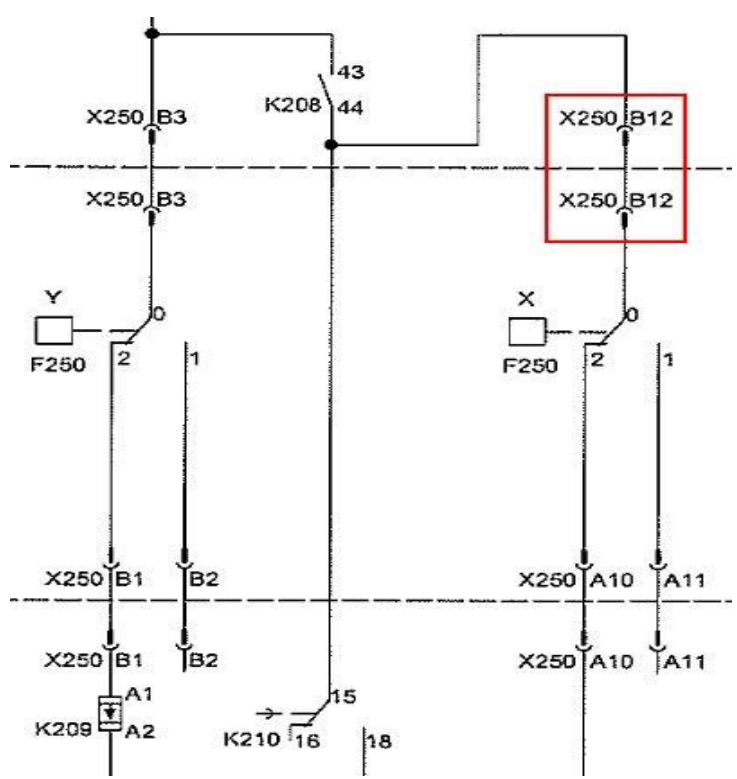

Figure 7. An example of error: incorrect terminal

341 The auxiliary contact K208 connected to X250 was found to occur on nine drawings. By examining the related drawings three of them indicated that the terminal A12 had been mislabelled as B12. If the site engineer had terminated the cables, as indicated by the drawing, the devices would have malfunctioned and thus jeopardizing the integrity and safety of the entire plant. The pressure switch is a critical component of the high voltage switchgear systems, which deals with the $138 \mathrm{kV}$ power circuit. A 'mistrip' of the equipment could have catastrophic consequences for the downstream devices and users. Similarly, the error identified in Figure 8 illustrates that terminal 1 of contact $\mathrm{S} 8 \mathrm{H}$ had been connected to the terminal A5 of socket X51. However, the correct connection should be terminal A5 of socket X15.

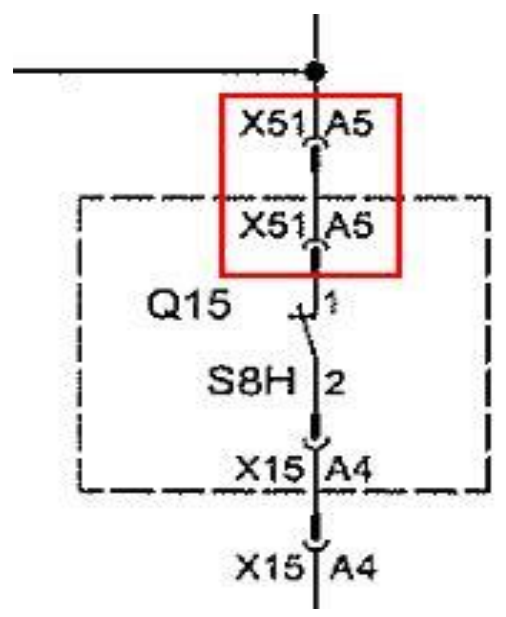


Figure 9 illustrates an error identified in a termination diagram. It is shown in Figure 9 that terminal 135 of a terminal strip is connected to the auxiliary relay K107. However, by checking the related drawings of the terminal strip it could be concluded that the terminal should be connected to circuit breaker F107 instead.

\begin{tabular}{|c|c|c|c|c|}
\hline$\times 269$ & $: 1$ & & & 138 \\
\hline $\mathrm{xy}$ & $: \mathrm{B6}$ & & . & 137 \\
\hline K208 & $: 6$ & & il & 136 \\
\hline K107 & $: 3$ & $70 \mathrm{~L}-$ & \begin{tabular}{|l|}
17 \\
$\mathrm{x}$
\end{tabular} & 135 \\
\hline K208 & $: 1$ & & $i$ & 134 \\
\hline $\mathrm{F} 107$ & $: 1$ & $70 \mathrm{~L}+$ & 1 & 133 \\
\hline K101 & $: A 2$ & & I & 132 \\
\hline F106 & $: 3$ & $60 \mathrm{~L}$ - & 11 & 131 \\
\hline K101 & $: \mathrm{A} 1$ & & $\hat{\imath}$ & 130 \\
\hline F106 & $: 1$ & $60 \mathrm{~L}+$ & & 129 \\
\hline
\end{tabular}

Figure 9. An example of error: incorrect equipment

Using a SIM to document the design of ECIS is more effective and efficient than using the CAD. A total of 80 man-hours was required for an engineer to create the SIM model for three Feeders compared to the 10,680 man-hours required using CAD. Assuming the hourly rate for a draftsman is $\mathrm{AU} \$ 130$ (this is the current market rate circa Sept. 2015), this equates to a saving of $\$ 1,401,400$ for a client or greater profits for the contractor. In addition to this saving, information redundancy is removed and errors or omissions are eliminated.

\section{Discussion}

'As-built' drawings seldom represent what has actually be constructed; this represents a persistent issue that is widely known amongst practitioners. This exposes an asset owner to elevated risk levels and adversely affects their ability to conduct operations and maintenance productively and safely. Needless to say, this does not necessarily mean what was actually installed was in accordance with the drawings; they may not have been simply up-dated by the engineers and draftsmen. Accordingly, the process of identifying and communicating errors to all project parties, and subsequently, the rectifying and up-dating of drawing comes into question A bit woolly Petey can we be a bit more precise here?

When confronted with time and resource constraints, engineers and draftsmen the sheer number of drawings requiring up-dating, may leave to selective prioritization where only the most important 
or imminent documents are modified. A plethora of scenarios may unfold here, but fundamentally the way in which ECIS are designed and documented needs to change in order to improve the integrity of assets, productivity and the competitiveness of firms specializing in providing design, engineering and contracting services. With the advent of BIM, it is expected that ECIS firms would adopt object-orientated approaches to align themselves with other disciplines and feed directly into a project's federated building information model. Explicitly, this is not the case and Hanna et al. $(2013$; 2014) reports upon the reluctance of electrical contractors to embrace BIM. In addressing this issue, education is pivotal to ensuring its BIM's or SIM? adoption, particularly as it requires engineers to switch from CAD to a new digital vis-a-vis paper based medium. Research, presented in this paper, provides a mechanism for ECIS engineers and contractors to realize that design and documentation can be undertaken more effectively and efficiently using a SIM, which is aligned with BIM.

\section{Conclusion}

Pete the conclusion is the weak link for me - as it represents a partial summary of the narrative not a conclusion of it. I personally would change tack and starts by introducing the problem and stating how much of a problem this is. Then go into some of what you did and quantify the palpable benefits of it as a means of demonstrating the value of this important work. I would conclude by discussing some of the issued that will be faced by culturally trying to reorientate a whole industry to this new method of working and what may be need to assist in this process. Maybe a final line then to just suggest some direction for future work... just my initial thoughts and happy to review this section again $;$

The quality of the 'As-built' documentation produced using CAD for a HVSS, which formed part of an up-grade of a SCADA for a geo-thermal power plant were evaluated. A total of 267 CAD drawings were examined for their errors and information redundancy and then used to create a SIM. The creation of the SIM required 80 man-hours, while to create the 267 CAD drawings required 10,860; a difference of 10,780. The empirical evidence clearly demonstrates that organizations that provide ECIS engineering and contracting services need to shift their mindsets from using CAD based systems where there exists a 1:n relationship, to one that focuses on establishing a 1:1 relationship between objects in the SIM and components in the real world. In doing so, it suggested that they will significantly improve the quality of their service, productivity and their competitiveness within their respective marketplaces. 
414 The authors would like to thank the participating contracting organization for making available this invaluable case study and providing access to the Dynamic Asset Documentation (DAD) Software. The authors would also like to acknowledge the financial support provided by the Australian Research Council (DP130103018), which enabled this research to be undertaken.

References References are a little light on the ground - I've highlighted places where a few more could be added to establish the context. Not essential though - more of a thought....

Clayton, M.J. Johnson, R.E., Song, Y., and Al-Qawasmi, J. (1998). A Study of Information Content of As-Built Drawings for USAA. CRS Center Texas A\&M University and USAA Facilities and Services, January (Accessed 18 th June 2015, available at: https://www.researchgate.net/publication/254694636_A_STUDY_OF_INFORMATION_CONTENT_OF_ASBUILT_DRAWINGS_FOR_USAA)

Gallaher, M.P., O'Connor, Dettbarn, J.L., and Gilday, L.T. (2004). Cost Analysis of Inadequate Interoperability in the US Capital Facilities Industry. US Department of Commerce Technology Administration, National Institute of Standards and Technology, Gaithersburg, Maryland, US.

Hanna, A.S. Boodai, F., and El Asmar, M. (2013). State of practice of building information modelling in mechanical and electrical construction industries. ASCE Journal of Construction Engineering and Management, 139(10), pp.

Hanna, A.S., Yeutter, M., and Aoun, D.G. (2014). State of practice of building information modelling in the electrical construction industry. ASCE Journal of Construction, Engineering and Management, 140(12), pp.

Lopez, R., and Love, P.E.D., (2012). Deign error costs in construction. ASCE Journal of Construction, Engineering and Management 138(5), pp.585-594.

Love, P.E.D. Zhou, J., Sing, C-P. and Kim, J.T. (2013). Documentation errors in instrumentation and electrical systems: Toward productivity improvement using system information modelling. Automation in Construction, 35, pp.448-459.

Love, P.E.D., Zhou, J., and Kim, J.T (2014). Assessing the impact of requests for information in electrical and instrumentation engineering contracts. Journal of Engineering Design, 25 (4-6), pp.177-193.

Love, P.E.D., Zhou, J. Matthews, J. and Carey, B. (2015). Toward productivity improvement using a systems information model. International Journal of Productivity and Performance Management,

Mills, A.J., Durepos, G., and Wiebe, E. (2010). Encyclopaedia of Case Study Research. SAGE Publications. 
Robson, C. (1993). Real World Research: A Resource for Social Scientists and Practitioner-Researchers. Blackwell Publishers, Oxford.

450 Tadt, E. Hanna, A., and White, D. (2012). Best practices from WisDOT Mega and ARRA Projects

451

452

453

454

455

456

457

458

459

\section{8} —request for information: benchmarks and metrics. WisDOT Policy Research Program Project, ID: 0092-1-20, Final Report, March 2012, Submitted to the Wisconsin Department of Transportation by the Construction and Materials Support Center, University of Wisconsin, Wisconsin, USA, 2012.

Zhou, J., Love, P.E.D., Matthews, J., Carey, B. and Sing, C-P. (2015). An object oriented model for life cycle management of electrical instrumentation control projects. Automation in Construction, 49, pp.142-151 